\title{
ВОПРОСЫ
}

\section{УЧЕТ СМЯГЧАЮЩИХ ОБСТОЯТЕЛЬСТВ ПРИ \\ НАЗНАЧЕНИИ НАКАЗАНИЯ ЛИЦУ, ЗАКЛЮЧИВШЕМУ ДОСУДЕБНОЕ СОГЛАШЕНИЕ О СОТРУДНИЧЕСТВЕ}

\begin{abstract}
Аннотация. В статье выясняется, какие смягчающие обстоятельства важны для характеристики основания применения правил, изложенных в 4.2 и $4 \mathrm{~cm} .62$ УК РФ, рассматривается вопрос о соотношении данных обстоятельств с основаниями для чрезвычайного смягчения наказания, предусмотренного ст. 64 УК РФ, а также освещаются иные аспекты применения смягчающих обстоятельств, включенных в соответствующий законодательный перечень.Утверждается, что назначение института досудебного соглашения о сотрудничестве заключается не только (а может быть, и не столько) в том, чтобы создать дополнительный стимул для активизации деятельности лица, совершившего преступление, по оказанию помощи органам, осуществляющим уголовное преследование, сколько в том, чтобы придать этой деятельности челенаправленность и эффрективность, прежде всего путем предъявления требования содействовать раскрытию или расследованию преступлений других лиц $4.1 \mathrm{~cm} .317 .6$ УПК РФ). На основании ряда умозаключений, подкрепленных данными судебной практики, автор приходит к выводу о том, что ч. $2 \mathrm{~cm} .62$ УК РФ следует изложить следующим образом: “Срок или размер наказания лицу, заключившему досудебное соглашение о сотрудничестве и предпринявшему все зависящие от него меры для исполнения взятых на себя обязательств, не может превышать ... (далее вариант смягчения наказания), если будет установлено, что данное лицо к тому же явилось с повинной либо активно способствовало раскрытию (расследованию) совершенного с его участием преступления или преступления, совершенного другим лицом (лицами)».

Ключевые слова: смягчающие обстоятельства, перечень смягчающих обстоятельств, учет смягчающих обстоятельств, содействие раскрытию преступления, явка с повинной, чрезвычайное смягчение наказания, досудебное соглашение, правила смягчения наказания, смягчение наказания, досудебное сотрудничество.
\end{abstract}

DOI: 10.7256/1729-5920.2014.1.9701

\footnotetext{
(C) Лобанова Любовь Валентиновна

* Доктор юридических наук, заведующая кафедрой Волгоградского государственного университета (в 1983 г. закончила Ярославский госуниверситет, в 1986 г. - аспирантуру; научный руководитель по кандидатской диссертации - профессор Я.О. Мотовиловкер; научный консультант по докторской диссертации - профессор Л.Л. Кругликов)

[up@volsu.ru]

400062, Россия, Волгоград, Университетский проспект, д. 100.
} 
马 еятельность, положительно влияющая на развитие уголовно-процессуальных отношений, должна учитываться, если даже она не сопряжена с фрактом раскаяния. Во-первых, эффективность уголовно-правового воздействия зависит среди прочего от того, насколько близко оно по времени к совершенному преступлению. Во-вторых, в силу принципиальных положений уголовного закона при определении объема ответственности учету подлежит любое положительное свойство личности, а значит, и проявляющееся во взаимоотношении с правоохранительными органами.

В этой связи нельзя не оценить как в целом положительное явление придание законодателем статуса обстоятельства, способного существенно уменьшить объем уголовной ответственности, содействию виновным в совершении преступления лицом его раскрытию или расследованию. Сказанное касается и установления специальных правил назначения наказания лицу, заключившему с государством досудебное соглашение о сотрудничестве (ч. 2 и ч. 4 ст. 62 УК РФ), применение которых уже, как пишут ученые и практики ${ }^{1}$, стало повсеместным.

Востребованность соответствующего института на практике тем не менее невелика. Так, в 2011 г. судами Российской Федерации в особом порядке рассмотрено более чем 500 тыс. уголовных дел, но при этом лишь 3 тыс. из них связаны с заключением досудебных соглашений ${ }^{2}$. Это не удивительно, поскольку остаются нерешенными вопросы, без ответа на которые входящие в рассматриваемое правовое образование нормы не могут нормально функционировать.

Так, по-прежнему остается неясным, с какими именно смягчающими обстоятельствами связан запрет на превышение установленного в ч. 2 ст. 62 УК РФ предела наказания. Указание в этой части на п. «и» ч. 1 ст. 61 Уголовного кодекса не проясняет ситуацию до конца. Во-первых, смущает то, что в ч. 2 ст. 62 УК РФ слово «обстоятельство» употреблено во множественном числе и, следовательно, закономерен вопрос, возможно ли предусмотренное

Колоколов Н.А. Практика назначения наказания лицу, с которым заключено досудебное соглашение о сотрудничестве // Уголовный процесс. 2010. № 11. С. 68; Тимошенко А. Досудебное соглашение о сотрудничестве: оценка эффективности процессуального института // Уголовное право. 2011. № 4. С. 106-111; Саркисянц Р. Роль прокурора в досудебном соглашении о сотрудничестве // Законность. 2012. № 8. С. 16-22 и др.

См.: Рубникович О. Правосудие предлагает массовую сделку // Коммерсантъ. 2012. 6 июня. здесь смягчение наказания только при одном из упоминаемых В п. «и» ч. 1 ст. 61 УК РФ смягчающих обстоятельств. При положительном ответе на данный вопрос высвечивается еще один проблемный аспект: сколько же в данном пункте перечислено самостоятельных оснований для смягчения - всего два или более? Не ясно и другое. В каком соотношении между собою находятся понятия «наличие смягчающих обстоятельств, предусмотренных п. «и» ч. 1 ст. 61 УК РФ, и «выполнение договора о сотрудничестве»? Может ли быть превышен указанный в ч. 2 ст. 62 УК РФ предел наказания (при отсутствии отягчающих обстоятельств), если подсудимый выполнил все обязательства, которые он брал на себя по досудебному соглашению о сотрудничестве? И, напротив, всегда ли невыполнение подобных обязательств должно повлечь за собой отказ в применении рассматриваемых правил?

Прежде чем определить нашу позицию по поставленным вопросам, приведем высказанные по ним суждения Е.В. Благова. «Снятию проблем, - пишет он, - не поможет ничего, кроме изменения закона. В п. «и» ч. 1 ст. 61 УК целесообразно ввести между указаниями на действия, образующие активное способствование предварительному расследованию, разделительные союзы «или», а для усиления альтернативности между указаниями на данные действия и явку с повинной разделительного союза «либо». В ч. 2 ст. 62 УК желательно вести речь о наличии хотя бы одного смягчающего обстоятельства, предусмотренного п. «и» ч. 1 ст. $61 »^{3}$. В то же время автор подчеркивает: «Видимо, законодатель имел в виду, что именно к действиям, названным в п. «и» ч. 1 ст. 61 УК, и должны сводиться те, «которые подозреваемый или обвиняемый обязуется совершить при выполнении им обязательств, указанных в досудебном соглашении о сотрудничестве». Совершение данных действий как раз и оценивается в качестве соответствующих смягчающих обстоятельств. Другое дело, что в ч. 2 ст. 62 УК акценты смещены с выполнения соглашения о сотрудничестве на их наличие, хотя последние могут иметь место и безотносительно первого» ${ }^{4}$.

Для уяснения точки зрения Е.В. Благова важным представляется еще одно содержащееся в той же работе положение.

\footnotetext{
Благов Е. Назначение наказания в случае заключения досудебного соглашения о сотрудничестве // Уголовное право. 2010. № 3. С. 23.

4 Там же. С. 24.
} 
Исходя из понимания явки с повинной, которое приводится в п. 7 постановления Пленума Верховного Суда РФ от 11 января 2007 г. № 2 «О практике назначения судами Российской Федерации уголовного наказания» ${ }^{5}$, а также из свойств субъекта, с которым заключается досудебное соглашение о сотрудничестве, Е.В. Благов высказывает сомнения в возможности учета при применении рассматриваемых правил явки с повинной. «Явке с повинной, заключает он, - здесь явно нет места» ${ }^{6}$.

Не все из приведенных суждений нам представляются верными. Однако мы, как и он, уверены, что ч. 2 ст. 62 УК РФ нуждается в коррекции. Редакция названной части не должна формировать у правоприменителя впечатление, будто содержащееся здесь правило может применяться лишь к лицу, которое явилось с повинной, заключило с государственным органом досудебное соглашение о сотрудничестве, а затем во исполнение этого договора активно содействовало раскрытию или расследованию преступления, изобличению и уголовному преследованию других соучастников, розыску имущества, добытого в результате преступления. Иначе применять этот институт окажется почти не к кому.

Согласны и с тем, что в ч. 1 ст. 61 УК РФ следует усилить акцент на альтернативность таких смягчающих обстоятельств, как явка с повинной и активное содействие раскрытию или расследованию преступления, хотя и предпочитаем другой способ для подобного акцентирования - рассредоточение данных смягчающих обстоятельств по разным пунктам (скажем, п. «и» и п. «и»). В то же время не считаем, будто из закона вытекает, что появление смягчающих обстоятельств в рассматриваемом случае связано именно с реализацией досудебного соглашения о сотрудничестве. Они, на наш взгляд, могут возникнуть и раньше.

Назначение института досудебного соглашения о сотрудничестве заключается не только (а может быть, и не столько) в том, чтобы создать дополнительный стимул для активизации деятельности совершившего преступление лица по оказанию помощи органам, осуществляющим уголовное преследование, сколько в том, чтобы придать этой деятельности целенаправленность и эффективность и прежде всего путем предъявления требования содействовать раскрытию или расследованию преступлений других лиц (ч. 1 ст. $317^{6}$ УПК РФ).

\footnotetext{
Бюллетень Верховного Суда РФ. 2007. № 4.

6 Благов Е. Указ. соч. С. 22.
}

Применение данного института целесообразно поэтому в следующих ситуациях:

1) при раскрытии (расследовании) групповых преступлений;

2) при раскрытии (расследовании) преступлений, совершенных при иной фрорме соучастия;

3) при раскрытии (расследовании) взаимосвязанных между собой преступных посягательств без признаков соучастия (скажем, ст. 290 и 291 (2911), 228 и 228 УК РФ и др.).

Излишне категоричным нам представляется суждение Т. Николаевой и Е. Ларкиной о том, будто из содержания уголовно-процессуального закона следует, что предметом соглашения должно являться содействие лица в раскрытии и расследовании именно того преступления, в связи с которым оно и приобрело статус подозреваемого или обвиняемого ${ }^{7}$. Судя по содержанию некоторых положений УПК РФ (п. 3 ч. 1 ст. $317^{5}$, п. 3 ч. 4 ст. $317^{7}$ ), использование данного института не исключено и для целей раскрытия преступлений, совершенных не сотрудничающим с государством лицом, если имеется иная связь между последним и совершившими данные преступления лицами. Например, п. 3 ч. 4 ст. $317^{7}$ УПК РФ предписывает суду при постановлении приговора в отношении подсудимого, с которым заключено соглашение о сотрудничестве, исследовать «преступления или уголовные дела, обнаруженные или возбужденные в результате сотрудничества с подсудимым».

В свете сказанного представляется вполне возможным говорить о наличии оснований для предусмотренного ч. 2 ст. 62 смягчения наказания и в том случае, когда реализация досудебного соглашения о сотрудничестве сама по себе не может быть расценена как активное содействие раскрытию или расследованию преступления. Такая активность, во-первых, может быть проявлена ранее, чем было заключено соглашение, а во-вторых, ее отсутствие может быть компенсировано явкой с повинной. Подтверждением сказанному могут служить и некоторые решения высшей судебной инстанции страны.

Так, оставляя в силе приговор Московского областного суда, вынесенный 19 февраля 2010 г. по делу К., осужденного по п. «ж», «з» ч. 2 ст. 105 и п. «а», «в» ч. 2 ст. 158 УК РФ, обосновывая справедливость назначенного наказания, Судебная коллегия по уголовным

Николаева Т., Ларкина Е. Некоторые вопросы заключения досудебного соглашения о сотрудничестве // Уголовное право. 2009. № 6. С. 87-88. 
делам Верховного Суда РФ подчеркнула: «Наказание назначено с учетом характера и степени общественной опасности совершенных преступлений, данных о личности К. и смягчающих обстоятельств, в том числе явки К. с повинной до заключения с ним досудебного соглашения, а также требований ч. 5 ст. $317^{7}$ УПК РФ, обязывающей судью при постановлении обвинительного приговора назначить подсудимому наказание с учетом положений ч. 2 и 4 ст. 62 УК РФ» 8 .

На наш взгляд, при констатации одного из этих смягчающих обстоятельств применение предусмотренного ч. 2 ст. 62 УК РФ поощрения возможно и в том случае, если заключившему досудебное соглашение о сотрудничестве удалось выполнить не все взятые на себя обязательства. Во-первых, среди этих обязательств могут оказаться такие, которые объективно не могли бы быть выполнены подозреваемым или обвиняемым. Во-вторых, невыполнение досудебного соглашения о сотрудничестве может иметь место и по вине должностных лиц, осуществляющих уголовное преследование, в частности в том случае, когда ими не обеспечена безопасность заключившего соглашение лица и (или) его близких. Логично предположить, что именно поэтому законодатель в ч. 2 ст. 62 УК РФ не называет выполнение соглашения о сотрудничестве в качестве условия смягчения наказания.

В связи со сказанным полагаем, что Пленум Верховного Суда РФ, указав в п. 19 постановления от 28 июня 2012 г. № 16 «О практике применения судами особого порядка судебного разбирательства уголовных дел при заключении досудебного соглашения о сотрудничестве» судам на необходимость принятия решения о прекращении особого порядка судебного разбирательства и назначении судебного разбирательства в общем порядке в случае, «если подсудимым не соблюдены все условия и не выполнены все обязательства, предусмотренные заключенным с ним досудебным соглашением о сотрудничестве ${ }^{9}$, вышел за пределы предоставленных ему полномочий. Подобного рода обстоятельства не называются в ст. $63^{1}$ УК РФ в качестве основания применения таковой, следовательно, не могут сами по себе обусловливать прекращение особого порядка судебного разбирательства.

Принципиальным же, думается, является то, что лицо предприняло все от него завися-

8 Кассационное определение Верховного Суда РФ от 8 апреля 2010 г. по делу № 4-010-33.

Бюллетень Верховного Суда РФ. 2012. № 8. щее для выполнения заключенного им соглашения о сотрудничестве. Этот момент, на наш взгляд, должен быть отражен в законе.

Часть 2 ст. 62 УК РФ предлагаем изложить следующим образом: «Срок или размер наказания лицу, заключившему досудебное соглашение о сотрудничестве и предпринявшему все зависящие от него меры для исполнения взятых на себя обязательств, не может превышать ... (далее вариант смягчения наказания), если будет установлено, что данное лицо к тому же явилось с повинной либо активно способствовало раскрытию (расследованию) совершенного с его участием преступления или преступления, совершенного другим лицом (лицами)».

Кроме того, нецелесообразно дробить в п. «и» ч. 1 ст. 61 УК РФ с помощью разделительных союзов одно и то же смягчающее обстоятельство, коим является активное способствование раскрытию или расследованию преступления, изобличению и уголовному преследованию других соучастников преступления, розыску имущества, добытого в результате преступления. Как подчеркнул в одном из своих решений Верховный Суд РФ, «изобличение других соучастников преступления и помощь в розыске имущества, добытого в результате преступления, - это формы способствования виновного раскрытию преступления» ${ }^{10}$.

В то же время, по нашему мнению, в перечне смягчающих обстоятельств следовало бы закрепить и такое обстоятельство, как активное содействие лица в раскрытии преступлений других лиц, которому не придано пока соответствующего статуса, хотя оно имеет немаловажное значение в реализации института досудебного соглашения о сотрудничестве. Интересно, что в Уголовном кодексе Китая данному обстоятельству присвоено даже значение основания чрезвычайного смягчения наказания (ст. 68) 11 .

В свете сказанного п. «и» ч. 1 ст. 61 УК РФ предлагается изложить в следующей редакции: «явка с повинной», а п. «и1», которым целесообразно дополнить названную часть, может быть сформулирован таким образом: «активное способствование раскрытию и (или) расследованию совершенного им или с его участием преступления либо преступления, совершенного другим лицом (другими

\footnotetext{
10 Бюллетень Верховного Суда РФ. 2005. № 4. С. 20-21.

11 Уголовный кодекс Китайской Народной Республики // Ахметшин X.M., Ахметшин Н.Х., Петухов А.А. Сoвременное уголовное законодательство КНР. М., 2000. C. 270 .
} 
лицами)». Указанием на новый пункт следует дополнить и ч. 1 ст. 62 УК РФ.

Подобные изменения в законодательном перечне смягчающих обстоятельств не нарушили бы тех разработанных теорий уголовного права принципов, которые должны соблюдаться при формировании подобных реестров: требования значительности, типичности, обязательности (безусловности) и строго определенной направленности влияния обстоятельства на назначение наказания ${ }^{12}$. Coдействие раскрытию преступлений других лиц способно и должно существенно сказываться на виде и размере наказания, причем однозначно в сторону его смягчения, независимо от того, принимало ли лицо, оказывающее помощь правоохранительным органам, участие именно в этом преступлении, раскрытию которого оно способствует, или лишь в связанном с таковым преступным деянием. И в том, и в другом случае речь идет о заслуге данного субъекта перед государством (в лице его правоохранительных органов), которая является свидетельством существенного снижения его степени общественной опасности. Подобное поведение вовсе не всегда диктуется раскаянием в том, что содеяно лично таким лицом. Но и то, что расположение государства виновный предпочел сохранению хороших отношений с другими преступниками (нередко более опасными), говорит в его пользу, указывая на то, что в его личности имеются качества, способные послужить опорной точкой в процессе исправления и предупреждения совершения новых преступлений.

Придание же содействию раскрытия преступлений, совершенных другими лицами, статуса обстоятельства, обязательно подлежащего учету при назначении наказания, должно, на наш взгляд, повысить роль институтов смягчения наказания и досудебного соглашения о сотрудничестве в раскрытии и расследовании преступлений, связанных между собою иными нитями, нежели узы соучастия (например, взяточничества, незаконного оборота оружия, незаконных действий с наркотическими средствами и др.).

В реформировании настоятельно нуждается ч. 4 рассматриваемой статьи. При ее конструировании, видимо, не сработала законодательная техника. Наименование статьи «Назначение наказания при наличии смягчающих обстоятельств» служит не очень надеж-

\footnotetext{
12 Кругликов Л.Л. Смягчающие и отягчающие обстоя тельства в советском уголовном праве. Ярославль, 1977. C. 18.
}

ной преградой для допущения, что ограничение верхнего предела наказания, назначенного лицу, заключившему досудебное соглашение о сотрудничестве, за преступление, за которое законом предусмотрено пожизненное лишение свободы либо смертная казнь, возможно при наличии одного фракта заключения подобного соглашения.

На наш взгляд, можно еще поставить под вопрос необходимость установления отсутствия отягчающих обстоятельств при применении ч. 4 ст. 62 УК РФ ${ }^{13}$. Но смысл закрепленного в этой части рассматриваемой статьи положения никак не может предполагать признания решающей роли в смягчении наказания за заключением договора о сотрудничестве между стороной защиты и обвинения, а не за той социально одобряемой деятельностью, которая должна быть осуществлена во исполнение данного договора или послужила поводом для подобного соглашения.

Правила смягчения наказания лицам, заключившим досудебное соглашение о сотрудничестве, если речь идет об их применении за различные по характеру и степени общественной опасности преступления, могут различаться в части установления пределов смягчения, но не оснований применения данных правил. Такого рода основания находятся в непосредственной зависимости от целей наказания, указанных в ч. 2 ст. 43 УК РФ, и могут быть охарактеризованы как фактическая ситуация, которая свидетельствует о возможности достижения данных целей без применения наказания, близкого к верхней границе, обозначенной в санкции статьи, предусматривающей ответственность за совершенное лицом преступление. Причем контуры подобной фактической ситуации обрисованы законодателем. Речь идет о такой помощи в раскрытии и (или) расследовании преступления, причем не только своего, но и чужого, которой в конечном счете придан предметный, целенаправленный характер.

Ответ на вопрос об учете смягчающих обстоятельств при назначении наказания лицу, заключившему досудебное соглашение о сотрудничестве, не исчерпывается выяснением круга обстоятельств, которые значимы для

\footnotetext{
В литературе на этот вопрос не так уж редко отвечают отрицательно (Брусницын Л.В. Сотрудничество со следствием: какие трудности в реализации новых норм УПК ожидают правоприменителя // Уголовный процесс. 2009. № 12. С. 14; Колоколов Н.А. Указ. соч. С. 70; Шаталов А.С. Заключение досудебного соглашения о сотрудничестве: правовая регламентация, достоинства и недостатки // Журнал российского права. 2010. № 5. С. 44).
} 
генезиса основания применения правил, закрепленных в ч. ч. 2 и 4 ст. 62 УК РФ. Нельзя также не обратить внимание на проявившуюся в связи с реализацией института досудебного соглашения о сотрудничестве, опасную тенденцию укрепления на практике позиции непризнания обязательности вошедших в законодательный перечень смягчающих обстоятельств. Отказ признавать обязательными указанные обстоятельства был легализован, как представляется, во многом благодаря точке зрения Пленума Верховного Суда РФ, изложенной в п. 8 его постановления от 11 января 2007 г. № 2 «О практике назначения судами Российской Федерации уголовного наказания ${ }^{14}$.

На наш взгляд, несмотря на неудачную редакцию некоторых пунктов ч. 1 ст. 61 УК РФ, никаких оснований для вывода о необязательном характере законодательного перечня смягчающих обстоятельств Уголовный кодекс не дает. Это убедительно доказано Л.Л. Кругликовым, справедливо подчеркивающим, что в отличие от Уголовного кодекса 1960 г. законодатель не делегировал суду права не признавать некоторые обстоятельства смягчающими. Если, рассуждает он, смягчающее обстоятельство «названо в перечне ч. 1 ст. 61 УК РФ, то признано оно таковым еще до возникновения уголовного дела самим законодателем, и в силу обязывающей функции перечня суду остается, выполняя волю законодателя, такое обстоятельство лишь выявить, зафиксировать, оценить, соотнести с другими обстоятельствами, характеризующими содеянное и личность виновного, и непременно принять все во внимание при выборе вида и размера (срока) наказания» ${ }^{15}$.

К сожалению, критические замечания, высказанные относительно названного пункта упомянутого постановления Пленума Верховного Суда РФ, не возымели своего действия. При претворении в жизнь норм о досудебном соглашении о сотрудничестве дело доходит до того, что применение такого рода смягчающих обстоятельств особо оговаривается в соответствующих соглашениях в качестве обязательства, которое берет на себя одна из сторон. Причем речь идет отнюдь не только об обстоятельствах, указанных в п. «и» и «к» ч. 1 ст. 61 УК РФ. Заключаются, например, договоры о реализации в

14 Бюллетень Верховного Суда РФ. 2007. № 4. С. 9.

15 Кругликов Л.Л. Проблемы теории уголовного права: избранные статьи. 2000-2009 гг. Ярославль, 2010 С. 381,386 . дальнейшем обстоятельства, обозначенного в том же п. «г» данной статьи.

Так, в содержание досудебного соглашения о сотрудничестве, заключенного стороной обвинения с К., осужденной приговором Волгоградского областного суда от 30 мая 2011 г. по совокупности преступлений, предусмотренных ч. 2 ст. 209, ч. 3 ст. 162, п. «а», «з» ч. 4 ст. 162, п. «а», «б» ч. 4 ст. 162 и п. «а» ч. 4 ст. 158 УК РФ к пяти годам лишения свободы с отбыванием его в исправительной колонии общего режима, включено следующее положение: «При соблюдении условий и обязательств данного соглашения при осуществлении в отношении обвиняемой К. уголовного преследования к ней могут быть применены смягчающие наказание обстоятельства, предусмотренные в п. «г», «и» ч. 1 ст. 61 УК РФ, а именно наличие малолетних детей ..., активное способствование раскрытию преступлений, изобличение других соучастников преступления» ${ }^{16}$. Подобная практика не случайна. В п. 7 ч. 2 ст. $317^{3}$ УПК РФ прямо говорится, что в досудебном соглашении о сотрудничестве указываются «смягчающие обстоятельства..., которые должны быть применены в отношении подозреваемого или обвиняемого при соблюдении последним условий и выполнении обязательств, указанных в досудебном соглашении о сотрудничестве». Не становятся ли в данных условиях смягчающие обстоятельства предметом торга вместо того, чтобы служить средством индивидуализации, а некоторые, «вес» которых законом определен, - и диффреренциации уголовной ответственности?

Угроза такого искажения роли смягчающих обстоятельств представляется вполне реальной. По этой причине целесообразно приведенное положение из п. 7 ч. 2 ст. 317.3 УПК РФ исключить. Никто, кроме законодателя, не вправе диктовать суду, какие обстоятельства он должен учесть в качестве смягчающих. Институт досудебного соглашения о сотрудничестве не отменяет ни принципиальных положений уголовного закона, ни общих начал назначения наказания, в том числе и положения о необходимости учета всех имеющих место смягчающих обстоятельств.

Реализация рассматриваемого института не может служить препятствием для признания установленных смягчающих обстоятельств основанием для чрезвычайного смягчения наказания, возможность которого

Архив Волгоградского областного суда за 2011 г. Дело № 2 -28/2011. 
оговорена в ст. 64 УК РФ. Причем речь идет не только о случаях обнаружения исключительных обстоятельств дела, существенно влияющих на степень общественной опасности совершенного лицом преступления, но и ситуациях констатации второго самостоятельного основания для такого рода смягчения наказания - активного содействия участника группового преступления его раскрытию. Между тем в юридической литературе в связи с закреплением в УК и УПК РФ института досудебного соглашения о сотрудничестве стали раздаваться голоса о необходимости отказа от этого основания для применения более мягкого наказания, чем предусмотрено за совершенное преступление. Так, А.А. Мясников пишет: «Целесообразно исключить из диспозиции ч. 1 ст. 64 УК РФ указание на такое обстоятельство, как активное содействие участника группового преступления раскрытию этого преступления. Допуская применение ст. 64 УК РФ, закон не связывает такое содействие с заключением досудебного соглашения о сотрудничестве (Глава 40.1 УПК РФ). Однако помощь в раскрытии группового преступления для того, чтобы служить исключительным смягчающим обстоятельством, должна быть официально установлена и подтверждена. Для этого существует процессуальный институт досудебного соглашения о сотрудничестве и специальные правила назначения наказания при наличии и соблюдении условий такого соглашения» ${ }^{17}$.

По нашему мнению, целесообразность реализации подобной рекомендации сомнительна. То, что наличие любого смягчающего обстоятельства нуждается в официальном подтверждении с помощью доказательств, не вызывает сомнения. Об этом прямо говорится в ст. 73 УПК РФ (п. 6 ч. 1). Однако ознакомившись со всеми обстоятельствами дела, суд в состоянии и без реализации института досудебного соглашения о сотрудничестве установить и обосновать наличие факта активного содействия раскрытию группового преступления со стороны его участника.

Не вполне корректно мотивировать исключение возможности применения к лицам, активно содействующим раскрытию группового преступления, положений ст. 64 УК РФ также и тем, что закон устанавливает для лиц, заключивших договор о сотрудничестве, в ч. 2 и 4 ст. 62 УК РФ иной вариант смягче-

\footnotetext{
17 Мясников А.А. Институт смягчения наказания: проблемы законодательной регламентации и правоприменения: автореф. дис. ... канд. юрид. наук. Краснодар, 2011. C. 21-22.
}

ния наказания. Ведь правила, содержащиеся в указанных статьях, в принципе не противоречат друг другу. Части 2 и 4 ст. 62 УК РФ обязывают суд лишь не выходить при наличии соответствующего смягчающего обстоятельства за пониженный для лиц, заключивших досудебное соглашение о сотрудничестве, верхний предел наказания, если отсутствуют отягчающие обстоятельства. А ст. 64 УК РФ предоставляет суду возможность выйти за низший предел санкции, устанавливающей ответственность за конкретное преступление. К тому же возможность такого смягчения назначения лицу, выполнившему досудебное соглашение о сотрудничестве, прямо оговорена в ч. 5 ст. $317^{7}$ УПК РФ.

Не совсем понятным в этой связи может показаться содержащееся в абз. 2 п. 12 постановления от 11 января 2007 г. № 2 «О практике назначения судами Российской Федерации уголовного наказания» следующее положение. «По смыслу закона, если смягчающие обстоятельства учтены судом при назначении наказания по правилам статьи 62 УК РФ, они сами по себе не могут повторно учитываться при применении статьи 64 УК РФ» ${ }^{18}$. Приведенное положение, на первый взгляд, явно противоречит логике закона. Оно также кажется противоречащим тому, о чем шла речь в первом абзаце того же пункта, т.е. утверждению о самостоятельности такого основания чрезвычайного смягчения наказания, как активное содействие участника группового преступления его раскрытию. Однако одно прочтение данного абзаца представляется вполне уместным. Для применения ст. 64 УК РФ нужно не наличие такого обстоятельства, как активное содействие участника группового преступления его раскрытию, а его особое содержание, исключающее предположение о том, что назначение наказания без выхода за нижний предел санкции будет справедливым. Активность поведения может быть различной как с точки зрения форм ее проявления, так и причин, вызывающих таковую, а равно результатов. Не случайно процессуальный закон предписывает суду исследовать в судебном заседании: «1) характер и пределы содействия подсудимого следствию в раскрытии и расследовании преступления, изобличении и уголовном преследовании других соучастников преступления, розыске имущества, добытого в результате преступления; 2) значение сотрудничества с подсудимым для раскрытия и расследования пре-

18 Бюллетень Верховного Суда РФ. 2007. № 4 
ступления, изобличения и уголовного преследования других соучастников преступления, розыске имущества, добытого в результате преступления; 3) преступления или уголовные дела, обнаруженные или возбужденные в результате сотрудничества с подсудимым; 4) степень угрозы личной безопасности, которой подвергался подсудимый в результате сотрудничества со стороной обвинения, его близкие родственники, родственники и близкие лица; 5) обстоятельства, характеризующие личность подсудимого, и обстоятельства, смягчающие и отягчающие наказание» (ч. 4 ст. $317^{7}$ УПК РФ). Исследование всех этих обстоятельств необходимо не только для того, чтобы выяснить, действительно ли подсудимый выполнил заключенное с ним досудебное соглашение о сотрудничестве, но и для того, чтобы определить меру поощрения его за позитивное посткриминальное поведение.

Таким образом, противоречие между ст. 64 и ст. 62 УК РФ, якобы возникшее в связи с введением института досудебного сотрудничества, на деле оказывается лишь кажущимся. Как верно замечает И. Звечаровский, институт назначения более мягкого наказания, чем предусмотрено за данное преступление, «не смешивается ни с одним институтом уголовного права, «работающим» на стадии назначения наказания в плане его смягчения» ${ }^{19}$ Однако чтобы минимизировать сомнения, возникающие по этому поводу, целесообразно внести коррективы в ст. 64 УК РФ, необходимо уточнить основания для чрезвычайного смягчения наказания. Для этого важно не только в максимально возможной степени обособить каждое из них, но и увязать данные основания, как это и ранее предлагалось в юридической литературе, с убеждением суда о возможности достижения целей наказания ${ }^{20}$. Один из вариантов редакции части первой данной статьи мог бы быть следующим: «При наличии исключительных обстоятельств, существенно уменьшающих степень общественной опасности преступления, в том числе связанных с целями и мотивами преступления, ролью виновного, его поведением во время или после совершения преступления, а равно при активном содействии участника группового преступления раскрытию этого преступления, суд, учитывая также данные о личности вино-

19 Звечаровский И. Институт назначения более мягкого наказания, чем предусмотрено за данное преступление // Уголовное право. 2012. № 2. С. 44.

20 Сундуров Ф.Р. Наказание и альтернативные меры в уголовном праве. Казань, 2005. С. 231. вного, может назначить осужденному наказание ниже низшего предела, предусмотренного соответствующей статьей Особенной части настоящего Кодекса, или избрать более мягкий вид наказания, чем предусмотрен этой статьей, или не применить дополнительный вид наказания, предусмотренный в качестве обязательного, если придет к убеждению, что такое смягчение наказания не препятствует достижению целей наказания, определенных настоящим Кодексом».

К сказанному о самостоятельности двух рассматриваемых институтов, предполагающих смягчение наказания, добавим еще несколько соображений.

Во-первых. Применение ст. 64 УК РФ в связи с активным содействием раскрытию преступления может осуществляться лишь в отношении участника группового преступления. Смягчение же наказания лицу, заключившему досудебное соглашение о сотрудничестве, возможно не только, как указывалось, при том условии, что раскрывается групповое преступление. Его применение не исключается и в случае установления фракта сотрудничества при раскрытии преступлений, совершенных при иной форме соучастия, а также взаимосвязанных между собою преступных посягательств без признаков соучастия.

Во-вторых, как было показано, применение положений ч. 2 и 4 ст. 62 УК РФ в принципе возможно и в том случае, когда такое смягчающее обстоятельство, как активное способствование раскрытию преступления, не будет установлено судом. Напротив, нарушение договора о сотрудничестве не всегда свидетельствует о том, что активное содействие раскрытию преступления как смягчающее обстоятельство отсутствует. Даже при обстоятельствах, о которых идет речь в ст. $63^{1}$ УК РФ, роль участника группового преступления в его раскрытии может оказаться значительной. В этой связи запрет на применение в случае нарушения договора о сотрудничестве ст. 64 УК РФ представляется излишне категоричным. Он не позволяет учесть ни причин нарушения соглашения, ни вины в этом отношении самих правоохранительных органов, ни психического отношения к допущенным упущениям со стороны обвиняемого (подозреваемого), ни наличия так называемых исключительных обстоятельств. В подобных условиях нарушение договора о сотрудничестве превращается в еще одно отягчающее обстоятельство, не включенное в соответствующий перечень, но способное нейтрализовать не только действие правил, специально предназначенных 
для смягчения наказания при заключении договора о досудебном сотрудничестве, но и исключить другие варианты уголовно-правового поощрения, а также обесценить некоторые смягчающие обстоятельства. А это представляется недопустимым.

Содержание ст. $63^{1}$ УК РФ целесообразно, на наш взгляд, изложить в следующей редакции: «В случае, если установлено, что лицом, заключившим досудебное соглашение о сотрудничестве, были представлены заведомо ложные сведения, способные затруднить ход расследования, либо умышленно скрыты от следователя либо прокурора обстоятельства, имеющие существенное значение для раскрытия преступления и (или) уголовного преследования участвующих в нем лиц, а равно не выполнены без уважительных причин условия указанного соглашения, суд назначает наказание в общем порядке без применения положений частей второй, третьей и четвертой статьи 62 настоящего Кодекса».

\section{Библиография:}

1. Благов Е. Назначение наказания в случае заключения досудебного соглашения о сотрудничестве // Уголовное право. - 2010. - № 3.

2. Брусницын Л.В. Сотрудничество со следствием: какие трудности в реализации новых норм УПК ожидают правоприменителя // Уголовный процесс. - 2009. - № 12.

3. Звечаровский И. Институт назначения более мягкого наказания, чем предусмотрено за данное преступление // Уголовное право. - 2012. - № 2.

4. Колоколов Н.А. Практика назначения наказания лицу, с которым заключено досудебное соглашение о сотрудничестве // Уголовный процесс. - 2010. - № 11.

5. Кругликов Л.Л. Смягчающие и отягчающие обстоятельства в советском уголовном праве. Ярославль, 1977.

6. Кругликов Л.Л. Проблемы теории уголовного права: избранные статьи. 2000-2009 гг. Ярославль, 2010.

7. Мясников А.А. Институт смягчения наказания: проблемы законодательной регламентации и правоприменения: автореф. дис. ... канд. юрид. наук. - Краснодар, 2011.

8. Николаева Т., Ларкина Е. Некоторые вопросы заключения досудебного соглашения о сотрудничестве // Уголовное право. - 2009. - № 6.

9. Рубникович О. Правосудие предлагает массовую сделку // Коммерсантъ. - 2012. - 6 июня.

10. Саркисянц Р. Роль прокурора в досудебном соглашении о сотрудничестве // Законность. 2012. - № 8.

11. Сундуров Ф.Р. Наказание и альтернативные меры в уголовном праве. - Казань, 2005.

12. Тимошенко А. Досудебное соглашение о сотрудничестве: оценка эффективности процессуального института // Уголовное право. - 2011. - № 4.

13. Шаталов А.С. Заключение досудебного соглашения о сотрудничестве: правовая регламентация, достоинства и недостатки // Журнал российского права. - 2010. - № 5.

\section{References (transliteration):}

1. Blagov E. Naznachenie nakazaniya $v$ sluchae zaklyucheniya dosudebnogo soglasheniya o sotrudnichestve / E. Blagov // Ugolovnoe pravo. - 2010. - № 3.

2. Brusnitsyin L.V. Sotrudnichestvo so sledstviem: kakie trudnosti v realizatsii novyih norm UPK ozhidayut pravoprimenitelya // Ugolovnyiy protsess. - 2009. - № 12.

3. Zvecharovskiy I. Institut naznacheniya bolee myagkogo nakazaniya, chem predusmotreno za dannoe prestuplenie // Ugolovnoe pravo. - 2012. - № 2.

4. Kolokolov N.A. Praktika naznacheniya nakazaniya litsu, s kotoryim zaklyucheno dosudebnoe soglashenie o sotrudnichestve // Ugolovnyiy protsess. - 2010. - № 11.

5. Kruglikov L.L. Smyagchayuschie i otyagchayuschie obstoyatelstva v sovetskom ugolovnom prave. - Yaroslavl, 1977.

6. Kruglikov L.L. Problemyi teorii ugolovnogo prava: izbrannyie stat., 2000-2009 gg. - Yaroslavl, 2010.

7. Myasnikov A.A. Institut smyagcheniya nakazaniya: problemyi zakonodatelnoy reglamentatsii i pravoprimeneniya: avtoref. dis. ... kand. yurid. Nauk. - Krasnodar, 2011.

8. Nikolaeva T., Larkina E. Nekotoryie voprosyi zaklyucheniya dosudebnogo soglasheniya o sotrudnichestve // Ugolovnoe pravo. - 2009. - № 6. 
9. Rubnikovich O. Pravosudie predlagaet massovuyu sdelku // Kommersant. - 2012. - 6 iyunya.

10. Sarkisyants R. Rol prokurora v dosudebnom soglashenii o sotrudnichestve // Zakonnost. 2012. - № 8.

11. Sundurov F.R. Nakazanie i alternativnyie meryi v ugolovnom prave . - Kazan, 2005.

12. TimoshenkoA. Dosudebnoe soglashenie o sotrudnichestve: otsenka effektivnosti protsessualnogo instituta // Ugolovnoe pravo. - 2011. - № 4.

13. Shatalov A.S. Zaklyuchenie dosudebnogo soglasheniya o sotrudnichestve: pravovaya reglamentatsiya, dostoinstva i nedostatki // Zhurnal rossiyskogo prava. - 2010. - № 5 .

Материал поступил в редакцию 24 сентября 2013 г. 